\title{
The Relevance of Water Vapour Transport for Water Vapour Sorption Experiments on Small Wooden Samples
}

\author{
Alexander Murr ${ }^{1}$ \\ Received: 2 October 2018 / Accepted: 20 February 2019 / Published online: 7 March 2019 \\ (c) The Author(s) 2019
}

\begin{abstract}
To characterise the sorption behaviour of wood or other hygroscopic materials with the use of water vapour sorption experiments, an accurate understanding of water vapour transport both to and through the sample material is necessary. Within the last decades, various modelling approaches on the sorption kinetics were developed, but there seems to be no general agreement on the relevance of water vapour transport. Using small amounts of grained wood, this study aims to estimate the influence of water vapour transport in sorption experiments on small sample sizes. A theoretical analysis based on a diffusion equation including a simplified sink/source term was carried out and compared with corresponding experiments. Nonlinear isotherm and temperature were shown to have a major impact on the effective diffusion of water vapour, whereas step size in humidity seems to mainly influence processes within the cell wall (e.g. relaxation and reorganisation of microstructure). Considering the paths of stagnant air above sample surface, the anomalous behaviour for a variation in sample thickness of grained wood can be explained. In conclusion, water vapour transport appreciably influences the sorption kinetics of small sample sizes and has to be considered in the modelling and interpretation of water vapour sorption experiments.
\end{abstract}

Keywords Sorption kinetics of grained wood - Water vapour sorption experiments · Modelling · Double diffusion · Blurred diffusion

\section{Introduction}

Water vapour sorption (WVS) experiments can be used to characterise the sorption behaviour of water vapour in wood. Sample material is placed into a climatic chamber where relative humidity $(\mathrm{RH})$ and temperature are varied. Changes in sample weight are measured at specific time intervals, which yields information on the amount of bound water in the sample. In addition to sorption isotherms (i.e. equilibrium values), sorption kinetics (i.e. time-dependent mass change) can provide further information on the sorption process and on material behaviour (e.g. Wadsö 1993b; Hill et al. 2011b). As water vapour transport (WVT) to the sur-

Alexander Murr

alexander.murr@gmx.at

1 Unit of Material Technology, University of Innsbruck, Technikerstraße 13, 6020 Innsbruck, Austria 
face and through the sample material is involved in experimentally obtained sorption kinetics, it is difficult to separate and identify processes that are taking place within the cell wall of wood (e.g. transport or relaxation and reorganisation of microstructure). Deviations from Fickian diffusion (i.e. anomalous or non-Fickian diffusion) like a concentration-dependent diffusion coefficient (e.g. Crank 1975), a two-stage sorption (e.g. Avramidis and Siau 1987; Wadsö 1994b) or differences in the diffusion coefficient between steady-state and transient sorption experiments (e.g. Wadsö 1994a and references therein) were frequently reported for wood and other polymers. Thus, in identifying the processes that take place within the cell wall of wood, a proper understanding of WVT is essential. To reduce the influence of WVT through the macrostructure (i.e. lumen, pits, rays), small microtomed or grained samples are frequently used (e.g. Hill et al. 2011b; Popescu et al. 2015). In previous experiments, measurements were taken at different temperatures (e.g. Hill et al. 2010b), step sizes in RH (e.g. Christensen and Kelsey 1959) and sample thickness (e.g. Wadsö 1993a; Eitelberger and Svensson 2012), and various modelling approaches were given in the literature (e.g. Skaar and Babiak 1982; Stanish 1986; Wadsö 1994a; Frandsen et al. 2007; Eitelberger et al. 2011; Krabbenhoft and Damkilde 2004; Olek et al. 2005; Hill et al. 2010a). However, the relevance of WVT on the sorption kinetics of such samples appears to still be undetermined (Himmel and Mai 2016).

To assess the importance of WVT in WVS experiments on small wooden samples, this study addresses the apparent gap in the literature of a separate investigation on the impact of a nonlinear sink, step size in relative humidity, temperature, moistening method and the paths of stagnant air above sample surface on the WVT during a step change in RH. Simulations were performed across a wide range of relative humidity and compared with corresponding experiments. This work thus provides a theoretical and experimental analysis on water vapour transport to and through wood by using a simplified sink/source in the diffusion equation and by comparing the results with WVS experiments on grained wood. Non-Fickian effects, the latent heat of sorption (see, for example, Christensen and Kelsey 1959) or other gradients in temperature, as well as a transport of bound water will not be treated in this study. The objective of this work is thus to understand the impact of water vapour transport rather than to provide a complete model to simulate the WVS kinetics of wood. An analytical discussion on the effective diffusion of water vapour is provided in Sect. 2. Details on the experimental setups are presented in Sect. 3. A comparison of the experimental results with corresponding numerical simulations is shown in Sect. 4. The given analysis can assist to estimate the relevant processes of WVT in WVS experiments on wood or other hygroscopic materials and to evaluate the applicability of certain modelling approaches.

\section{Theory}

In analysing the impact of water vapour transport on the sorption kinetics of grained or cut wood, care has to be taken about the uptake/release of $\mathrm{H}_{2} \mathrm{O}$ molecules of the sample material and the water vapour supply properties of the measuring device. The sample material acts as a variable sink/source in the transport process, and the impact on WVT can be investigated with constant step sizes in RH along the nonlinear isotherm, variations in $\Delta \mathrm{RH}$ step size and variations in temperature. For the latter, only the case of a constant temperature variation (i.e. no gradients) will be analysed. The impact of the measuring device on WVT to the sample surface can be characterised by the moisture exchange method inside the measuring chamber as well as by considering the paths of stagnant air caused by the use of sample 
bowls. In the following, transport processes will be discussed on the basis of an ordinary diffusion equation combined with an instantaneous sink. Two further simplifications will be used: transport through the thickness of the cell wall will be assumed to be very fast (i.e. all sorption sites are immediately available) and a transport along the cell wall will be neglected (see Sect. 4 and, for example, Christensen and Kelsey 1959; Hozjan and Svensson 2011). This simplified treatment on the WVS kinetics of wood should not replace more advanced modelling approaches but rather provide a better understanding on the relevance of WVT in WVS experiments.

\subsection{Influence of Sample Material}

Nonlinear sink Describing the transport of water vapour through a binary mixture of water vapour and air, the mass flux of water vapour $j_{\mathrm{wv}}=j_{\mathrm{wv}}(x, t)$ (in $\mathrm{kg} \mathrm{s}^{-1} \mathrm{~m}^{-2}$ ) in one dimension can be described as (Bird et al. 2002)

$$
j_{\mathrm{wv}}=j \cdot \frac{\rho_{\mathrm{wv}}}{\rho}-\rho D_{a} \cdot \frac{\partial}{\partial x}\left(\frac{\rho_{\mathrm{wv}}}{\rho}\right)
$$

with $\rho_{\mathrm{wv}}=\rho_{\mathrm{wv}}(x, t)$ being the local mass concentration of water vapour (in $\mathrm{kg} \mathrm{m}^{-3}$ ), $\rho=\rho(x, t)$ the local mass concentration of the water vapour-air mixture, $j=j(x, t)$ the sum of water vapour and air mass flux and $D_{\mathrm{a}}=D_{\mathrm{a}}(x, t)$ the diffusion coefficient of water vapour into air (in $\mathrm{m}^{2} \mathrm{~s}^{-1}$ ). Assuming the total pressure and temperature to be constant during the interdiffusion of the two gases and treating the two gases as ideal gases, the mass flux of water vapour can be evaluated as

$$
j_{\mathrm{wv}}=\frac{-D_{\mathrm{a}}}{1+\frac{\mathrm{m}_{\mathrm{Air}}-\mathrm{m}_{\mathrm{H}_{2} \mathrm{O}}}{\mathrm{m}_{\mathrm{H}_{2} \mathrm{O}}} \cdot \frac{\rho_{\mathrm{wv}}}{\rho}} \cdot\left(\frac{\partial \rho_{\mathrm{wv}}}{\partial x}-\frac{\rho_{\mathrm{wv}}}{\rho} \cdot \frac{\partial \rho}{\partial x}\right) .
$$

$\mathrm{m}_{\mathrm{H}_{2} \mathrm{O}}$ is the molecular weight of water and $\mathrm{m}_{\text {Air }}$ the mean molecular weight of dry air. As the water vapour concentration at room temperature is much smaller than the concentration of the water vapour-air mixture, Eq. 1 can be simplified to

$$
j_{\mathrm{wv}} \simeq-D_{\mathrm{a}} \cdot \frac{\partial \rho_{\mathrm{wv}}}{\partial x}
$$

with an error of less than $1.2 \%$ for $T=25^{\circ} \mathrm{C}$. Using the equation of continuity, an ordinary diffusion equation can thus be derived for the diffusion of water vapour through air. Applying the binary diffusion for wood, care has to be taken about the uptake or release of $\mathrm{H}_{2} \mathrm{O}$ molecules during the diffusion of water vapour through wood. Thus, a corresponding sink/source term has to be introduced to take account of these effects. For a one-dimensional diffusion process, this leads to (see, for example, Crank 1975)

$$
\frac{\partial \rho_{\mathrm{wv}}}{\partial t}=\frac{\partial}{\partial x}\left(D_{\mathrm{wv}} \cdot \frac{\partial \rho_{\mathrm{wv}}}{\partial x}\right)-\frac{\partial s}{\partial t}
$$

with $s=s(x, t)$ being the local mass concentration of bound $\mathrm{H}_{2} \mathrm{O}$ molecules. The water vapour diffusion coefficient $D_{\mathrm{wv}}=\xi \cdot D_{\mathrm{a}}$ is given by the reduction factor $\xi$ to account for the porous structure of wood (e.g. Stanish 1986; Krabbenhoft and Damkilde 2004) and the diffusion coefficient of water vapour in air $D_{\mathrm{a}}=D_{\mathrm{a}}\left(p_{\mathrm{wv}}, T\right)$ (e.g. Schirmer 1938; VDIGesellschaft 2006), which slightly depends on partial water vapour pressure $p_{\mathrm{wv}}$. Using a nonlinear relationship between the free and bound $\mathrm{H}_{2} \mathrm{O}$ molecules

$$
s\left(\rho_{\mathrm{wv}}\right)=R\left(\rho_{\mathrm{wv}}\right) \cdot \rho_{\mathrm{wv}},
$$


and assuming a constant volume for the sample material (i.e. no swelling/shrinkage), the nonlinear function $R=R\left(\rho_{\mathrm{wv}}\right)$ can be evaluated as

$$
R=\frac{s\left(\rho_{\mathrm{wv}}\right)}{\rho_{\mathrm{wv}}}=\frac{M_{\mathrm{b}}\left(\rho_{\mathrm{wv}}\right)}{V_{\mathrm{S}} \cdot \rho_{\mathrm{wv}}} .
$$

Here $M_{\mathrm{b}}\left(\rho_{\mathrm{wv}}\right)$ is the local amount of bound water in wood at a given water vapour concentration and $V_{\mathrm{S}}$ is the sample volume. To analyse the effect of a nonlinear isotherm on the diffusion process, the sink factor $\Delta R$ will be introduced

$$
\Delta R=\frac{1}{V_{\mathrm{S}}} \cdot \frac{M_{\mathrm{b}}^{f}-M_{\mathrm{b}}^{i}}{\rho_{\mathrm{Wv}}^{f}-\rho_{\mathrm{wV}}^{i}}
$$

with superscript letters indicating the final and initial value of the given quantities. Using an averaged value for $D_{\mathrm{wv}}\left(\rho_{\mathrm{wv}}\right)$ over a step change in $\mathrm{RH}$, one can simplify Eq. 2 to an ordinary diffusion equation

$$
\frac{\partial \rho_{\mathrm{wv}}}{\partial t}=\frac{\bar{D}_{\mathrm{wv}}}{1+\Delta R} \cdot \frac{\partial^{2} \rho_{\mathrm{wv}}}{\partial x^{2}}=D_{\mathrm{eff}} \cdot \frac{\partial^{2} \rho_{\mathrm{wv}}}{\partial x^{2}}
$$

with a constant effective diffusion coefficient $D_{\text {eff }}$ for the given step change. The diffusion process is thus slowed down approximately by the speed factor $(1+\Delta R)^{-1}$ as a consequence of sample material acting as a sink for adsorption (or a source for desorption). Corresponding to the nonlinear isotherm, the effective diffusion coefficient—and thus the diffusion process through the sample material—varies with humidity.

Variation in $\triangle \mathrm{RH}$ Step Size In order to analyse the impact of a variation in step size of humidity, care has to be taken about the actual and initial value of both bound and free concentration of $\mathrm{H}_{2} \mathrm{O}$ molecules. Assuming the applicability of the general gas equation, a linear relation between water vapour concentration and relative humidity can be established

$$
\rho_{\mathrm{wv}}(\mathrm{RH})=\frac{\mathrm{RH}}{100} \cdot \frac{p_{\mathrm{sat}}(T)}{T} \cdot \frac{\mathrm{m}_{\mathrm{H}_{2} \mathrm{O}}}{\mathrm{k}_{\mathrm{B}}}
$$

with $T$ representing the temperature (in $\mathrm{K}$ ), $\mathrm{RH}$ the relative humidity (in per cent) and $\mathrm{k}_{\mathrm{B}}$ the Boltzmann constant. The saturation pressure can be expressed with an empirical relationship as given, for example, in Alduchov and Eskridge (1996)

$$
p_{\text {sat }}(T)=6.019 \cdot \exp \left(\frac{17.625 \cdot(T-273.15)}{T-30.11}\right) \mathrm{Pa} .
$$

Variation in Temperature To model the impact of temperature on the behaviour of WVT through wood, the temperature-dependent diffusion coefficient of water vapour in the air has to be considered. A nonlinear relation is given by the empirical expression (e.g. VDIGesellschaft 2006)

$$
D_{\mathrm{a}}\left(p_{\mathrm{wv}}, T\right)=\frac{2.252}{p_{0}+p_{\mathrm{wv}}} \cdot\left(\frac{T}{T_{0}}\right)^{1.81} \frac{\mathrm{Pa} \cdot \mathrm{m}^{2}}{\mathrm{~s}}
$$

with $T_{0}=273.15 \mathrm{~K}$ and $p_{0}$ the atmospheric pressure (in Pa). For a constant humidity, $D_{\mathrm{a}}$ is increasing with temperature. Additionally, the concentration of water vapour in the air and partly the concentration of available sorption sites in the sample material depend on temperature (see, for example, Hill et al. 2010b). Using Eqs. 3, 4 and 6 and assuming the sample volume to be approximately constant with temperature, the nonlinear function $R\left(\rho_{\mathrm{wv}}, T\right)$ for two different temperatures $T_{1}$ and $T_{2}$ can be expressed as 


$$
\frac{R\left(T_{2}\right)}{R\left(T_{1}\right)}=\frac{M_{\mathrm{b}}\left(T_{2}\right)}{M_{\mathrm{b}}\left(T_{1}\right)} \cdot \frac{T_{2}}{T_{1}} \cdot \frac{p_{\text {sat }}\left(T_{1}\right)}{p_{\text {sat }}\left(T_{2}\right)}
$$

for a given value of RH. Making use of the sink factor over a step change in humidity (cf. Eq. 5), the effective diffusion coefficient can be approximated as

$$
D_{\text {eff }}(T)=\frac{\xi \cdot \bar{D}_{a}(T)}{1+\Delta R(T)} .
$$

Hence, the effective water vapour transport through the wooden sample material depends on the temperature dependence of both the diffusion coefficient of water vapour in the air and the sink factor. It should be noted that this work only analyses the case of a constant change in temperature. Any local variations in temperature (in space or time) would need a separate treatment to include the resulting transfer of energy (see, for example, Thorvaldsson and Janestad 1999; Eitelberger et al. 2011).

\subsection{Influence of Measuring Method}

Moistening Method The moistening unit of the measuring apparatus takes a certain time to change humidity during a step change in RH and thus has an impact on the measured sorption kinetics of wood. Assuming the applicability of the general gas law, the amount of $\mathrm{H}_{2} \mathrm{O}$ molecules for a given volume, relative humidity and temperature can be estimated as

$$
M_{\mathrm{wV}}(V, \mathrm{RH}, T)=V \cdot \frac{\mathrm{RH}}{100} \cdot \frac{p_{\mathrm{sat}}(T)}{T} \cdot \frac{\mathrm{m}_{\mathrm{H}_{2} \mathrm{O}}}{\mathrm{k}_{\mathrm{B}}} .
$$

Without any sample material in the measuring chamber, the necessary amount of water to change humidity during a step change in RH can be calculated with Eq. 10 by replacing $\mathrm{RH}$ with $\Delta \mathrm{RH}$. Humidity inside the measuring chamber can be exchanged with an inflow of either dry air (or any other carrier fluid), water vapour-saturated air or a mixture of both (corresponding to the desired $\mathrm{RH}$ ). In each case, the rates for the inflow and outflow have to be taken into account. The change in $\mathrm{H}_{2} \mathrm{O}$ molecules $\mathrm{d} N(t)$ in a given volume is given by the difference between the incoming and leaving molecules,

$$
\begin{aligned}
\mathrm{d} N & =\mathrm{d} N_{\mathrm{I}}-\mathrm{d} N_{\mathrm{o}} \\
& =\frac{\rho_{\mathrm{I}} \cdot r_{\mathrm{I}}-\rho_{\mathrm{o}} \cdot r_{\mathrm{o}}}{\mathrm{m}_{\mathrm{H}_{2} \mathrm{O}}} \mathrm{d} t
\end{aligned}
$$

with $r_{\mathrm{I}, \mathrm{o}}$ indicating the rates for the inflow and outflow (in $\mathrm{m}^{3} \mathrm{~s}^{-1}$ ) and $\rho_{\mathrm{I}, \mathrm{o}}$ the corresponding mass concentrations. In order to provide a constant total pressure inside the measuring chamber, equal rates have to be ensured $\left(r_{\mathrm{I}}=r_{\mathrm{o}}\right)$. With the simplification of an instantaneous mixing of added and existent moisture, the concentration in the outflow is identical to the concentration inside the chamber $\left(\rho_{\mathrm{o}}=\rho_{\mathrm{wv}}\right)$. Making use of $N(t)=\rho_{\mathrm{wV}}(t) \cdot V_{\mathrm{M}} \cdot \mathrm{m}_{\mathrm{H}_{2} \mathrm{O}}{ }^{-1}$, changes in concentration of water vapour in the measuring volume $V_{\mathrm{M}}$ can be estimated as

$$
\mathrm{d} \rho_{\mathrm{wV}}(t)=\frac{r_{\mathrm{I}}}{V_{\mathrm{M}}} \cdot\left(\rho_{\mathrm{I}}-\rho_{\mathrm{vw}}(t)\right) \mathrm{d} t
$$

for a constant total pressure. Integrating $\mathrm{d} \rho_{\mathrm{wV}}(t)$ for a step change in humidity and using Eq. 6, the increase in RH in the measuring chamber can be approximated in the absence of sample material as

$$
\mathrm{RH}(t)=\mathrm{RH}_{\mathrm{I}}-\left(\mathrm{RH}_{\mathrm{I}}-\mathrm{RH}_{\mathrm{i}}\right) \cdot \exp \left(-\frac{r_{\mathrm{I}} \cdot t}{V_{\mathrm{M}}}\right) .
$$


Here, $\mathrm{RH}_{\mathrm{i}}$ is the starting value of relative humidity for the step change and $\mathrm{RH}_{\mathrm{I}}$ the relative humidity of the inflow. Depending on the used water vapour sorption system, $\mathrm{RH}_{\mathrm{I}}$ and $r_{\mathrm{I}}$ have to be taken either for dry air, water vapour-saturated air or for the desired RH (for systems where the two streams are mixed to the set $\mathrm{RH}$ value before injecting it into the measuring chamber). The minimal time for a step change in humidity inside the measuring chamber could thus be roughly estimated, if the moistening unit uses the maximum rates for the inflow from initial to final RH (i.e. no reduction in the flux to avoid overshooting). With the use of sample material in the measuring chamber, the change in humidity during a step change in $\mathrm{RH}$ will be slowed down as a consequence of the adsorption/desorption of $\mathrm{H}_{2} \mathrm{O}$ molecules. To give a rough estimate, the sample material will be assumed to be in direct contact with the forced water vapour-air stream and instantaneously change the concentration of water vapour by the uptake/release of $\mathrm{H}_{2} \mathrm{O}$ molecules. Following a similar derivation as before, Eq. (11) will be modified by

$$
\mathrm{RH}(t)=\mathrm{RH}_{\mathrm{I}}-\left(\mathrm{RH}_{\mathrm{I}}-\mathrm{RH}_{\mathrm{i}}\right) \cdot \exp \left(-\frac{r_{\mathrm{I}} \cdot t}{V_{\mathrm{M}}+\Delta R \cdot V_{\mathrm{S}}}\right)
$$

for the case of small sample sizes. Hence, the effect of sample material on the change in humidity inside the measuring chamber can be approximately treated by increasing the measuring volume with $\Delta R \cdot V_{\mathrm{S}}$. The time to reach $\mathrm{x} \%$ of the final $\mathrm{RH}$ value during a step change in RH can thus be approximated for small wooden samples as

$$
t_{x}=-\frac{V_{\mathrm{M}}+\Delta R \cdot V_{\mathrm{S}}}{r_{\mathrm{I}}} \cdot \ln \left(1-\frac{\mathrm{RH}_{f}-\mathrm{RH}_{\mathrm{i}}}{\mathrm{RH}_{\mathrm{I}}-\mathrm{RH}_{\mathrm{i}}} \cdot x\right) .
$$

Paths of Stagnant Air For WVS experiments on larger pieces of cut wood, sample material can be directly exposed to the forced water vapour-air stream. Rosen (1978) demonstrated that flow velocities above a certain value are needed to reduce the influence of an external resistance. In the case of small microtomed or grained wood, sample material is usually too light to be placed directly in the forced stream. Thus, sample bowls are used to protect them from being removed (e.g. Hill et al. 2010b). As the microtomed and grained samples are not in direct contact with the water vapour-air stream, water vapour has to diffuse a certain distance to reach the surface of the sample (see Fig. 1). Therefore, an additional diffusive transport along the path $H_{\mathrm{A}}$ has to be taken into account,

$$
\frac{\partial \rho_{a}}{\partial t}=\frac{\partial}{\partial x}\left(D_{\mathrm{a}} \cdot \frac{\partial \rho_{a}}{\partial x}\right)
$$

with $\rho_{a}=\rho_{a}(x, t)$ being the mass concentration of water vapour in the forced stream. To match Eq. 2 with Eq. 14, an identical flux can be used at the sample surface. For the following, the joint treatment of water vapour diffusion to and through the grained sample will be termed as double-diffusion model. The importance of a boundary layer above the sample surface has also been mentioned for the cup method (e.g. Eitelberger and Svensson 2012 and references therein), where a film boundary condition for cut samples was used instead.

\section{Materials and Methods}

\subsection{Sample Preparation}

Sample material was taken from the lower third of the stem of Norway spruce wood (Picea abies) grown at an altitude of $1200 \mathrm{~m}$. To determine the annual rings, a plank was cut 


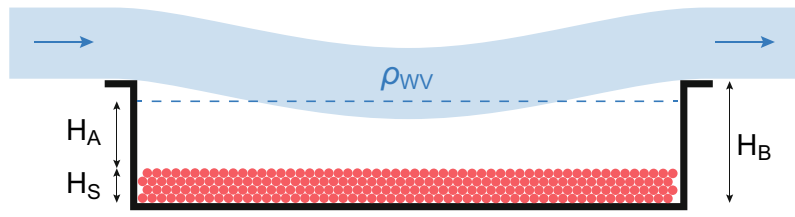

Fig. 1 Simplified streamlines for the movement of forced water vapour-air stream over the sample material. Dashed line indicates the mean penetration of water vapour $\rho_{\mathrm{WV}}$ for the forced stream; $H_{\mathrm{A}}$ is the corresponding diffusion length, $H_{\mathrm{S}}$ the sample height and $H_{\mathrm{B}}$ the height of the bowl

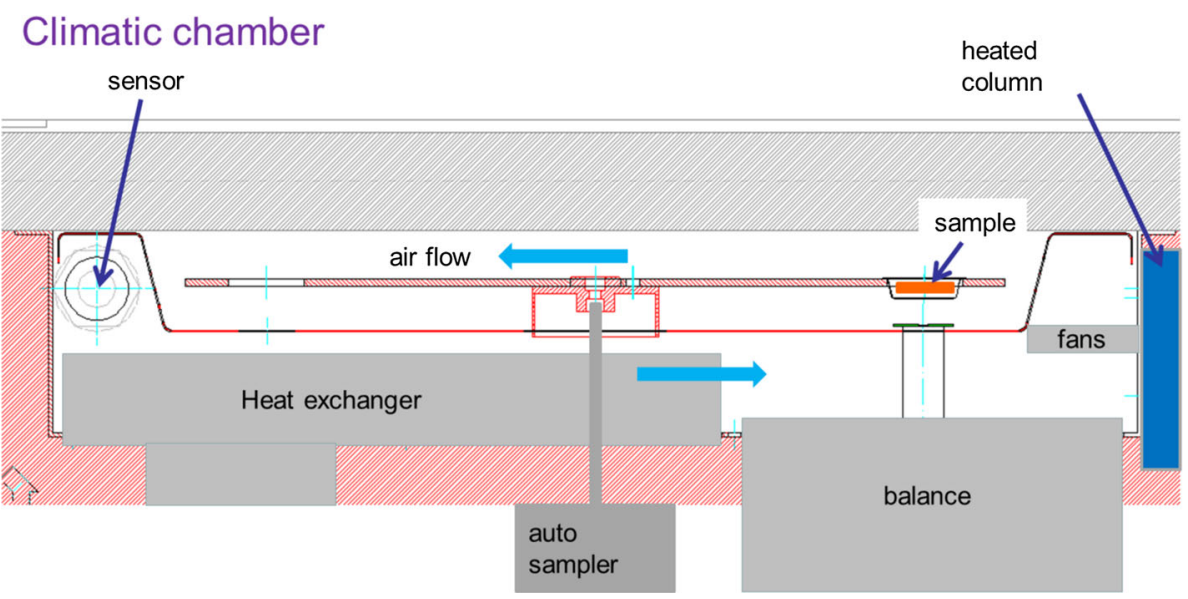

Fig. 2 Schematic illustration of the water vapour sorption system SPSx-1 $\mu$. Source: ProUmid

from the centre of the tree in longitudinal direction. After a drying phase of 3 months at a relative humidity of approximately $40 \%$ and a temperature around $22{ }^{\circ} \mathrm{C}$, the density has been determined to be $\rho_{W}=450 \pm 40 \mathrm{~kg} \mathrm{~m}^{-3}$. The plank was ground omitting the inner and outer annual rings to obtain a more homogeneous sample material. A double-sieving process using a set of seven analysis sieves was conducted to obtain five grain size distributions between $20 \mu \mathrm{m}$ and $1 \mathrm{~mm}$. This was done to restrict the grain size variation to a known particle diameter range. To cross-check the particle size, a laser diffraction analysis was performed.

\subsection{Measuring Method}

To measure the sorption kinetics of grained wood, the water vapour sorption system SPSx$1 \mu$ (ProUmid GmbH, Germany) was used. The sample material was placed into aluminium bowls (cf. Fig. 1) and exposed to a variation in humidity at a pre-defined temperature. Adsorption/desorption of $\mathrm{H}_{2} \mathrm{O}$ molecules was measured using a gravimetric weighting process. The bowls had an inner diameter of $d_{B}=51 \mathrm{~mm}$ and a height of $H_{B}=13 \mathrm{~mm}$ to prevent the grained sample material from being removed by the forced water vapour air stream. Up to 11 sample bowls can be placed on a rotating plate inside the measuring chamber (Fig. 2). A microscale with a reproducibility of $\pm 10 \mu \mathrm{g}$ successively records the mass change of each sample. To correct the amount of adsorbed water on the sample bowls as well as a possible scale drift, an additional reference bowl is weighted before the first and after the last sample. A linear change in mass and a linear drift between the two measurements were assumed. 
Table 1 Grained wood classified by sample mass (weighted at $\mathrm{RH}=20 \%$ ) and minimal to maximal particle size for the experimental investigations

\begin{tabular}{ll}
\hline Sample mass $(\mathrm{mg})$ & Particle size $(\mu \mathrm{m})$ \\
\hline 20 & $63-125$ \\
200 & $63-125$ \\
400 & $63-125$ \\
600 & $63-125$ \\
40 & $63-125$ \\
40 & $250-500$ \\
200 & $63-125$ \\
200 & $250-500$ \\
\hline
\end{tabular}

Inside the measuring chamber, the humidity sensor is placed on the opposite side of the humidification inlet and two fans distribute the moistened air with a velocity of $0.3 \mathrm{~m} / \mathrm{s}$. Each time a sample is placed on the scale, humidification and fans are turned off. To regulate humidity, either dry $\left(\mathrm{RH}_{\mathrm{dry}}=0.2 \% \mathrm{RH}\right.$; hereinafter referred to as $\left.0 \%\right)$ or water vapour-saturated air $\left(\mathrm{RH}_{\text {sat }} \approx 99 \% \mathrm{RH}\right)$ is passed through the inlet until target humidity is reached. The maximum flow rate for dry air was set to $4.2 \mathrm{dm}^{3} \mathrm{~min}^{-1}$ and for saturated air to $2.4 \mathrm{dm}^{3} \mathrm{~min}^{-1}$. It has to be mentioned that this method of regulating RH is not how the most commonly used water vapour sorption systems operate. With the integrated Peltier element, temperature can be varied around the ambient temperature with the consequence of a reduced humidity range. The moistening unit is also controlled by temperature to provide water vapour-saturated air with an appropriate saturation pressure. Relative humidity can be changed stepwise with an arbitrary step size between $0 \%$ and $95 \% \mathrm{RH}$ for a temperature of $25^{\circ} \mathrm{C}$. Within the given humidity range, a variance below $\pm 0.5 \% \mathrm{RH}$ can be ensured except for $\mathrm{RH} \leq 1 \%( \pm 0.1 \% \mathrm{RH})$ and $\mathrm{RH} \geq 80 \%( \pm 1 \% \mathrm{RH})$. Deviations in temperature were below $\pm 0.1^{\circ} \mathrm{C}$, and the measurement cycle time was adjusted to the number and amount of sample material to provide a stabilised climate.

\subsection{Experimental Set-Up}

Two different experimental investigations were performed. To analyse the impact of the nonlinear isotherm and paths of stagnant air, four different filling levels with a grain size of $63-125 \mu \mathrm{m}$ were used. Sample weight was chosen to be $20 \mathrm{mg}, 200 \mathrm{mg}, 400 \mathrm{mg}$ and $600 \mathrm{mg}$ (see Table 1). Relative humidity was changed in steps of $\Delta \mathrm{RH}=10 \%$ from $0 \%$ to $90 \%$ $\mathrm{RH}$, followed by a step of $\Delta \mathrm{RH}=5 \%$ to reach the maximum of $95 \% \mathrm{RH}$. Subsequently, a reverse order sequence was used for desorption. Temperature was set to $25^{\circ} \mathrm{C}$ during the whole measurement. The influence of temperature and step size in $\mathrm{RH}$ on the sorption kinetics of wood was analysed with two grain size distributions of 63-125 $\mu \mathrm{m}$ and $250-500 \mu \mathrm{m}$, and a weight of $40 \mathrm{mg}$ and $200 \mathrm{mg}$, respectively (Table 1). The latter grain size distribution was used to check the kinetics for larger grains and is not shown in the results. Temperatures were set to $20^{\circ} \mathrm{C}, 25^{\circ} \mathrm{C}$ and $30^{\circ} \mathrm{C}$ to minimise changes in material properties. For each temperature, relative humidity was changed in steps of $\Delta \mathrm{RH}=10 \%$ from $0 \%$ to $90 \% \mathrm{RH}$ followed by a reverse order sequence. The maximum of humidity was set to $90 \% \mathrm{RH}$ to compare the results for the various temperatures, as for $T=20^{\circ} \mathrm{C}$ condensation effects inside the measuring chamber started to appear at $\mathrm{RH}=95 \%$. Additionally, a measurement with $\Delta \mathrm{RH}=30 \%$ was performed to analyse the differences in equilibrium values for two distinct step sizes. For both set-ups, grained wood was poured into the sample bowls and weighted at RH $=20 \%$ and $T=25^{\circ} \mathrm{C}$. Sample mass was chosen with an accuracy of 
$\pm 0.2 \mathrm{mg}$ for a weight below $40 \mathrm{mg}$ and $\pm 1 \mathrm{mg}$ above $200 \mathrm{mg}$. A spatula was used to flatten the surface and to avoid any compressions among the grains. Measurement cycle time was set to $8 \mathrm{~min}$ based on a pre-experiment. Prior to testing, samples were conditioned inside the measuring chamber for at least $24 \mathrm{~h}$ at $\mathrm{RH}=0.2 \%$ and a temperature corresponding to the given investigation. To provide a better reproducibility, a complete run from $0 \%$ to $95 \%$ $\mathrm{RH}$ (followed by the reverse order decreasing sequence) was performed in advance. This was observed in pre-experiments and has also been suggested in the literature (e.g. Popescu and Hill 2013). After each step change, RH was kept constant until all samples reached the equilibrium condition, which was defined as

$$
\frac{\mathrm{d}}{\mathrm{d} t}\left(\frac{m(t)}{m_{0}}\right) \leq 0.02 \%
$$

in a 120 min period. This mass stability criterion for a mass change in less than $0.0002 \% \mathrm{~min}^{-1}$ should provide a lower error in the equilibrium moisture content than the most commonly used criterion of $0.002 \% \mathrm{~min}^{-1}$ (see Glass et al. 2017). The condition to initiate the next step change in RH was calculated with a linear regression based on the sample mass $m(t)$ and its minimum value $m_{0}$ after preconditioning at $0.2 \% \mathrm{RH}$.

\subsection{Simulations}

The software Wolfram Mathematica 10.4 was used for all simulations in Sect. 4. Differential equations were solved using a numerical differential equation solver, which provides the solutions as interpolating function objects. The measured and interpolated $\mathrm{RH}$ values of the humidity sensor were used as boundary conditions for the forced water vapour air stream at the height $H_{\mathrm{A}}$ above the sample surface. For the diffusion of water vapour through grained wood, a vanishing flux was used at the bottom of the sample bowls. The measured mass changes were interpolated with a first-order polynomial function to obtain a continuous function. To provide the necessary continuous equilibrium values (i.e. sorption isotherms) for the solver, the Hailwood-Horrobin model (Hailwood and Horrobin 1946) was adjusted to the measured data. Where not stated separately, a reduction factor of $\xi=0.9$ was used for the transport through the porous structure of wood (see Frandsen et al. 2007). Alternatively, a reduction factor can be constructed by using the porosity and the effective transport path length through granular materials (Penman 1940). The height of the grain layers inside the sample bowls was calculated with the simplification of a hexagonal close packing of identical spherical particles (Murr and Lackner 2018)

$$
H_{\mathrm{S}}=2 \gamma r(1-\sqrt{2 / 3})+12 \sqrt{2} \frac{\gamma^{3} M_{\mathrm{S}}}{d_{B}^{2} \pi^{2} \rho_{\mathrm{W}}},
$$

where a correction factor $\gamma=1.31$ is included to account for a larger radius given by the non-idealised grained wood particles. Here, $r$ denotes the radius of the particles, $M_{\mathrm{S}}$ the sample mass, $d_{\mathrm{B}}$ the diameter of the sample bowl and $\rho_{\mathrm{W}}$ the density of wood. Eq. 15 was used as it allows to distinguish the differences in sample height more clearly than given by the roughly measured values.

\subsection{Error Estimation}

In regard to the measurement error, two different sources must be taken into account. Particularly in the medium range of humidity (where the least amount of $\mathrm{H}_{2} \mathrm{O}$ molecules is 
taken up/released by the samples for a given RH step), the scale reproducibility is important to consider. For the $20 \mathrm{mg}$ sample with $\Delta \mathrm{RH}=10 \%$, the amount of adsorbed or desorbed water varies between $0.29 \mathrm{mg}$ and $1.1 \mathrm{mg}$ each step. Hence, the random error caused by the scale contributes between $\pm 1 \%$ and $\pm 3.5 \%$ and decreases with increasing sample mass. The second type of error arises from local and global variations in humidity inside the measuring chamber. It is influenced by the regulation of humidity, the large amount of water taken up/being released by the wooden samples, as well as by the relative position between humidity inlet, sample position and humidity sensor (Fig. 2). This systematic error was observed to increase at temperatures below and above $25^{\circ} \mathrm{C}$ and is important for the comparison of various temperatures as well as in the range of high humidity. It varies between $0.5 \%$ and $2 \%$ for the $200 \mathrm{mg}$ sample and shows an increase of $10 \%$ for $T=30^{\circ} \mathrm{C}$ or $15 \%$ for $T=20^{\circ} \mathrm{C}$. Consequently, in the comparison of various sample weights (Sect. 4.5) scale reproducibility is the dominant source of error, whereas in the comparison of various temperatures (Sect. 4.3) the error caused by local and global variations in humidity is of greater concern. Using the propagation of error, the error for a comparison of two incorrectly measured quantities in the standardised representation can be calculated as

$$
\Delta\left(\frac{m_{M_{200}}}{m_{M_{20}}}\right)=\frac{\Delta m_{M_{200}}}{m_{M_{20}}}+\left(\frac{m_{M_{200}}}{m_{M_{20}}}\right) \cdot \frac{\Delta m_{M_{20}}}{m_{M_{20}}} .
$$

The total error in the comparison of the $200 \mathrm{mg}\left(m_{M_{200}}\right)$ and $20 \mathrm{mg}\left(m_{M_{20}}\right)$ sample in the standardised representation thus depends on the error of the single quantities $\left(\Delta m_{M_{200}}\right.$ and $\Delta m_{M_{20}}$ ) as well as on the actual value for the sample masses (see Sect. 4.5). Errors caused by an irregular packing of the grained particles or edge effects (see, for example, Penman 1940) are assumed to be negligible. Concerning the variations in sample material, the effect of differences in cell wall thickness, annual ring position and inhomogeneities in longitudinal and transversal direction of the tree stem were minimised by graining a large wooden plank. Thus, an appropriate average value for the sample material and for the mass increase of the grains can be assumed. Given the large amount of grains inside the sample bowls, an averaged value for the measured sorption kinetics was ensured for all samples.

\section{Results and Discussion}

With a few mentioned exceptions, simulations were done numerically to provide more accurate results than the analytical approximation presented in Sect. 2. Still, the simplifications of an instantaneous sink, a fast transport across the cell wall and neglecting transport along the cell wall were used. The latter two simplifications might be justified by calculating the necessary time of diffusion for $\mathrm{H}_{2} \mathrm{O}$ molecules through and along the cell wall. Using the bound water diffusion coefficient in the order of $10^{-12} \mathrm{~m}^{2} \mathrm{~s}^{-1}$ (Siau 1984), a mean cell wall thickness of $4 \mu \mathrm{m}$ and a cell wall length of $180 \mu \mathrm{m}$ (i.e. the mean radius of the $250-500 \mu \mathrm{m}$ grain size), the time to reach $90 \%$ of the equilibrium value can be evaluated to be $<1 \mathrm{~min}$ (across the cell wall) and $>120 \mathrm{~min}$ (along the cell wall). Comparing these values with the experimental measured value of approximately $15 \mathrm{~min}$ (for the step change $0 \% \rightarrow 10 \% \mathrm{RH}$ ), the two simplifications seems to be plausible. 


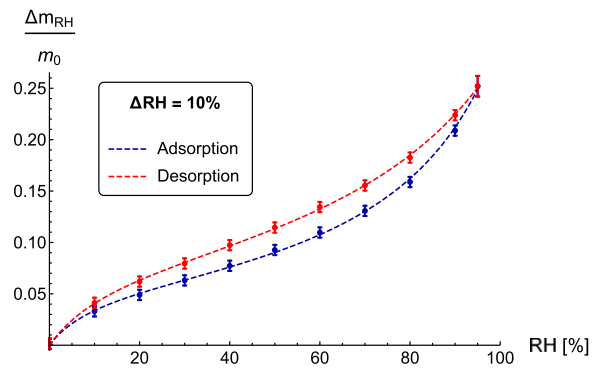

(a)

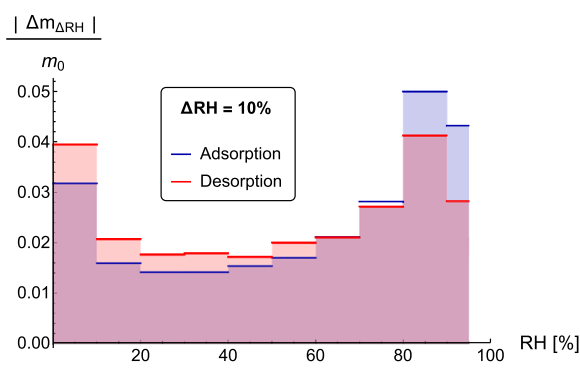

(b)

Fig. 3 Adsorption and desorption isotherm for grained wood at $T=25^{\circ} \mathrm{C}(\mathbf{a})$. Markers indicate the measured equilibrium values and dashed lines the fitted results based on the Hailwood-Horrobin model. Absolute values for the mass increase or decrease each step change in $\mathrm{RH}$ are shown in $\mathbf{b}$. Error bars were omitted for a better comparability

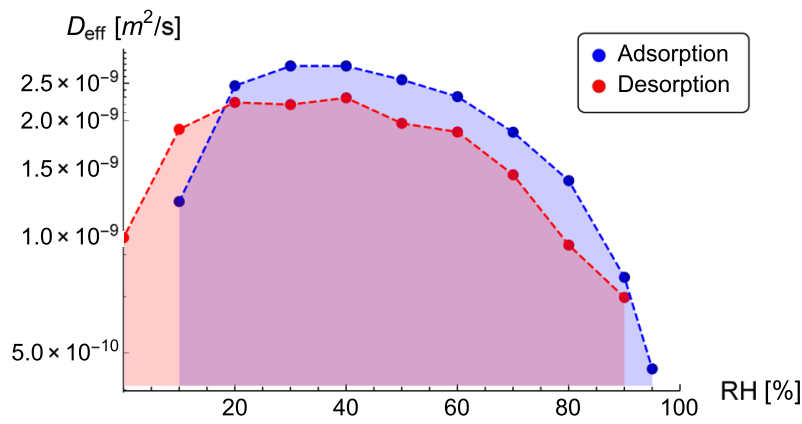

Fig. 4 Effective diffusion coefficient for adsorption and desorption at $T=25^{\circ} \mathrm{C}$. Markers indicate the calculated average values for a step change in RH shown at the final value of the $\Delta \mathrm{RH}$ step and dashed lines are solely for illustration (linear interpolation). Error bars were omitted for a better comparability

\subsection{Nonlinear Sink}

To investigate the influence of a nonlinear sink on the diffusion of water vapour through grained wood, a sample of $200 \mathrm{mg}$ with a calculated grain layer height of $0.68 \mathrm{~mm}$ was used. The nonlinear adsorption isotherm and the scanning desorption isotherm are shown in Fig. 3a, and the uptake/release of $\mathrm{H}_{2} \mathrm{O}$ molecules in each step is given in Fig. 3b. Both the shape of the isotherms and the hysteresis indicate a strong interaction between the $\mathrm{H}_{2} \mathrm{O}$ molecules and the cell wall polymers. Hence, a clustering of $\mathrm{H}_{2} \mathrm{O}$ molecules within the cell wall of wood (Barrie and Platt 1963) should not have a significant impact on the following results. Using Eqs. 5, 8 and 9 with the given experimental results, the variation in the effective diffusion coefficient can be calculated (see Fig. 4 ). Corresponding to the minimum of adsorbed or desorbed water between 20 and $50 \%$ RH, the effective diffusion coefficient shows a maximum in the medium range of humidity. Similar results were also reported in the literature (Gouanvé et al. 2006), where the measured initial mass increase of flax fibres was used to evaluate the diffusion coefficient. A calculation of the effective water vapour diffusion coefficient (Eqs. 5, 6, 7, 8 and 9) for various wooden samples (i.e. cut, grained and cell wall material) is shown in Table 2. These values were calculated for adsorption and the values for desorption are within this range. Comparing the approximate value of $2.510^{-5} \mathrm{~m}^{2} \mathrm{~s}^{-1}$ for the diffusion coefficient of water vapour in air (Eq. 8), a decrease of 3 to 4 magnitudes for grained wood and 4 to 
Table 2 Variation in effective diffusion coefficient $D_{\text {eff }}$ for a step change of $\Delta \mathrm{RH}=10 \%$ between $0 \%$ and $95 \% \mathrm{RH}$ for various wooden samples at $T=25^{\circ} \mathrm{C}$

\begin{tabular}{lcl}
\hline Sample material & Mean density $\left[\mathrm{kg} \mathrm{m}^{-3}\right]$ & Effective diffusion coefficient $\left[\mathrm{m}^{2} \mathrm{~s}^{-1}\right]$ \\
\hline Grained wood & 145 & $5 \times 10^{-9} \ldots 3 \times 10^{-8}$ \\
Cut wood & 450 & $1.5 \times 10^{-9} \ldots 9 \times 10^{-9}$ \\
Cell wall material & 1500 & $4.5 \times 10^{-10} \ldots 3 \times 10^{-9}$ \\
\hline
\end{tabular}

5 magnitudes for wood cell wall material was calculated for the effective WVT. A similar attenuation factor for the water vapour transport through cut wood has been found by Stanish (1986). Hence, even when using an instantaneous sink and constant boundary conditions on the sample surface, the diffusion process of water vapour through small wooden samples (during a step change in $\mathrm{RH}$ ) will be markedly retarded as a consequence of the uptake/release of $\mathrm{H}_{2} \mathrm{O}$ molecules. With a typical value of $10^{-12}$ to $10^{-10} \mathrm{~m}^{2} \mathrm{~s}^{-1}$ for the longitudinal bound water diffusion coefficient (e.g. Siau 1984), the effective water vapour diffusion coefficient lies almost in a comparable range. It might be noted that a steady-state diffusion coefficient for spruce wood in longitudinal direction of $1.510^{-9} \mathrm{~m}^{2} \mathrm{~s}^{-1}$ is mentioned by Wadsö (1993b). Consequently, the water vapour transport has to be considered in WVS experiments on wood, even in the case of small sample sizes. A neglection of the WVT as, for example, in the bound water diffusion model (Olek et al. 2005; Olek and Weres 2007) seems thus to be inappropriate for a description of the WVS behaviour of wood (see also, for example, Stanish 1986). Further, the similar magnitude for the characteristic time $\tau_{1}$ of the fast process in the PEK model for adsorption and desorption (Hill et al. 2010a) might be a consequence of effective water vapour diffusion. The fast process could thus be related to the diffusion of water vapour to and through the sample material. Regarding the relevance of WVT for small wooden samples, a pure mechanical interpretation of the measured sorption kinetics (e.g. Hill et al. 2011a) seems therefore to be inappropriate. Similar results have also been mentioned in the literature (Murr and Lackner 2018).

\subsection{Variation in $\Delta R H$ Step Size}

Comparing different step sizes in $\mathrm{RH}$, care has to be taken with relaxation and reorganisation processes within the cell wall of wood (e.g. Christensen and Kelsey 1959) as well as with the ratio between the amount of water taken up/being released by the sample and the added amount of water vapour in the measuring chamber during the step change. Whereas the influence of the former is not treated in this work as it requires an appropriate model for the source/sink, the latter can be evaluated within the given framework presented in Sect. 2. An analysis of the speed factor $(1+\Delta R)^{-1}$ with Eq. 5 is shown in Fig. 5. Corresponding to the different water uptake/release each step change in RH (cf. Fig. 3b), a variation in the speed factor (and hence a variation in the effective diffusion coefficient) can be obtained for adsorption (Fig. 5a) and desorption (Fig. 5b). Larger values indicate a faster equilibration and correspond to less water uptake/release during the step change. The order of magnitude of both step sizes is comparable as both change in sample mass and change in water vapour increase for an increasing step size in RH. However, for an accurate comparison of the kinetic behaviour between two different step sizes (e.g. $0 \% \rightarrow 10 \% \mathrm{RH}$ with $0 \% \rightarrow 30 \% \mathrm{RH}$ ), these differences in the speed factor have to be taken into account to precisely identify processes that take place within the cell wall of wood. It should be noted that an initial limitation of water 


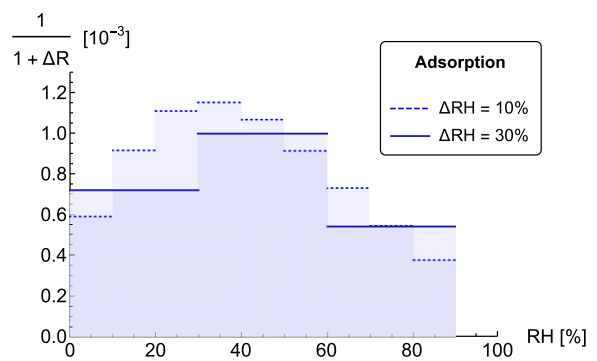

(a)

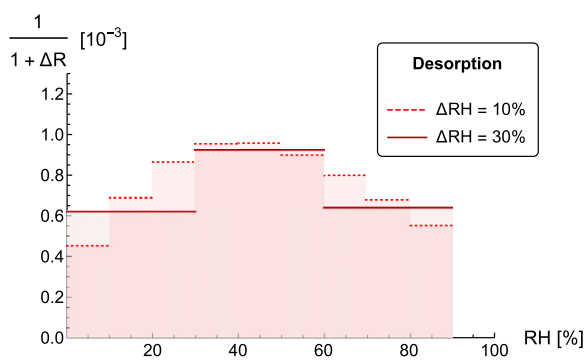

(b)

Fig. 5 Comparison between the speed factor $(1+\Delta R)^{-1}$ for the diffusion coefficient for a step change in $\mathrm{RH}$ with $\Delta \mathrm{RH}=10 \%$ and $\Delta \mathrm{RH}=30 \%$ at $T=25^{\circ} \mathrm{C}$. Adsorption is shown in a and desorption in b. Error bars were omitted for a better comparability

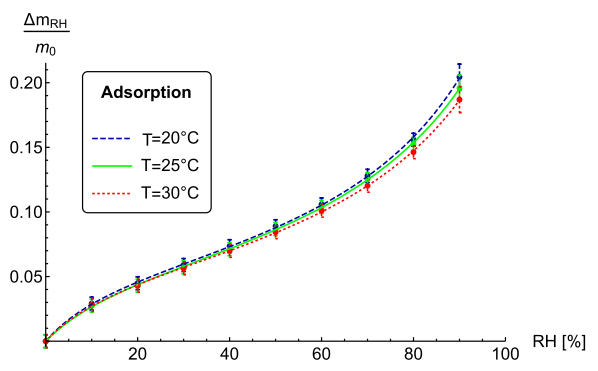

(a)

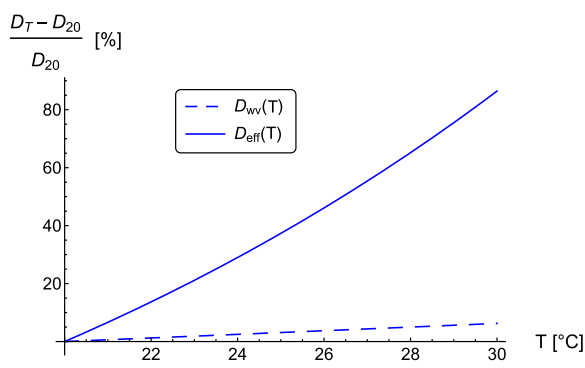

(b)

Fig. 6 Variations in the adsorption isotherm with temperature for the $200 \mathrm{mg}$ sample (a) and calculated relative changes of the diffusion coefficient for the step change $0 \% \rightarrow 10 \% \mathrm{RH}(\mathbf{b})$. For the latter, solid line shows the (interpolated) water vapour diffusion coefficient through wood including instantaneous adsorption of $\mathrm{H}_{2} \mathrm{O}$ molecules (i.e. effective diffusion) and dashed line the water vapour diffusion coefficient through wood without including adsorption

vapour supply caused by the fixed feed rate of water vapour-saturated or dry air becomes more relevant for larger step changes in $\mathrm{RH}$, as more water vapour has to be provided by the moistening unit (see Eq. 13).

\subsection{Variation in Temperature}

To analyse the influence of temperature on the sorption kinetics of wood, three different temperatures were used. As shown in Fig. 6a, the adsorption isotherms are only slightly affected by temperature. An increasing deviation can be seen in the higher range of RH, with a larger amount of water taken up at lower temperatures. Similar results were obtained for desorption, where a more pronounced difference between the isotherms was observed. Hill et al. (2010b) have shown similar results, even though in the high range of RH the isotherms were closer together. Comparing the influence of temperature on the water vapour diffusion coefficient without uptake/release of $\mathrm{H}_{2} \mathrm{O}$ molecules $\left(\mathrm{D}_{\mathrm{wv}}=\xi \cdot D_{\mathrm{a}}\right)$ and on the effective water vapour diffusion coefficient (Eq. 9), considerable differences are shown in Fig. 6b. With the former showing a relative variation of approximately $6 \%$ between 20 and $30^{\circ} \mathrm{C}$, the latter varies more than $80 \%$ in the same range. These differences are a consequence of the amount of water taken up by the wooden samples at a given RH varying only slightly 


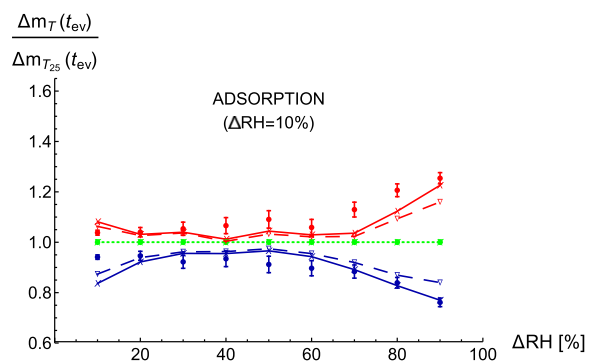

(a)

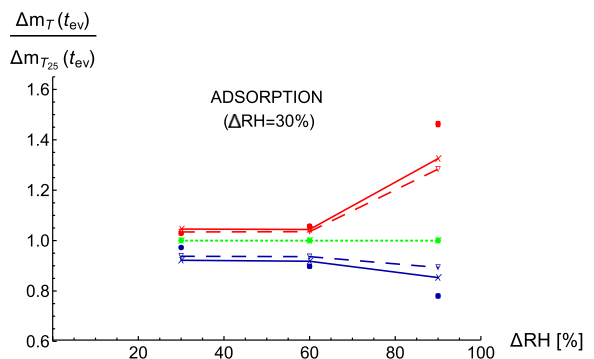

(c)

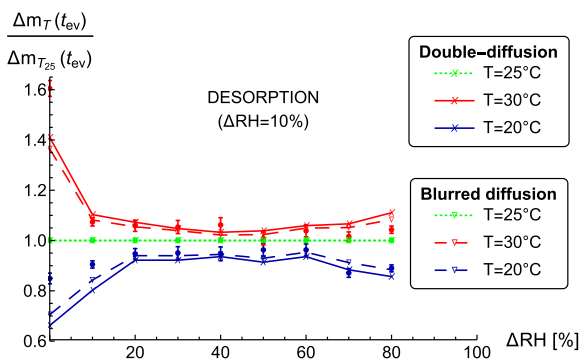

(b)

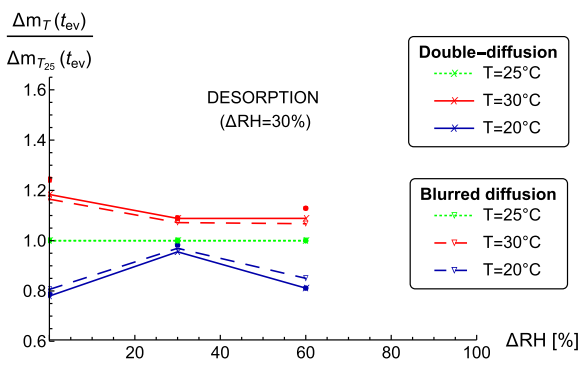

(d)

Fig. 7 Comparison of relative mass change for three temperatures with $\Delta \mathrm{RH}=10 \%(\mathbf{a}, \mathbf{b})$ and $\Delta \mathrm{RH}=$ $30 \%$ (c, d). Markers with error bars indicate the measured values and markers with solid/dashed lines the corresponding simulations of the double-diffusion model and the blurred diffusion model (linear interpolation is solely for illustration)

with temperature (see Fig. 6a), whereas the amount of $\mathrm{H}_{2} \mathrm{O}$ molecules in air at the same RH changes significantly with temperature (see Eqs. 5-9). An analysis of measured sorption kinetics with simulated results for the water vapour transport to and through grained wood is given in Fig. 7. Mass increase and decrease were evaluated at $t_{\mathrm{ev}}=15 \mathrm{~min}$ and normalised to the values at $T=25^{\circ} \mathrm{C}$. Evaluation time was chosen by a reasonable compromise to capture the diffusive processes at the beginning of the mass changes and to provide at least two measuring cycles (to perform an interpolation of the measured data). Results were shown for the $200 \mathrm{mg}$ sample with a grain size distribution of $63-125 \mu \mathrm{m}$, as the kinetics were too fast for the $40 \mathrm{mg}$ sample and the relative errors too large to detect any significant differences. The split-up with temperature could be roughly captured with the double-diffusion model for adsorption (Fig. 7a) and desorption (Fig. 7b). For the simulations, Eqs. 2 and 14 were used with $s\left(\rho_{\mathrm{wv}}\right)=\frac{M_{\mathrm{b}}\left(\rho_{\mathrm{wv}}\right)}{V_{\mathrm{S}}}$ and effective diffusion length $H_{\mathrm{A}}+H_{\mathrm{S}}$ was chosen to be $60 \%$ of the sample bowl height. Additionally, an evaluation with a simple diffusion process was performed, where the sorption sites were assumed to be equally distributed within the water vapour penetration depth and the bottom of the sample bowl. This non-realistic approach will be termed as blurred diffusion model and might be used for certain engineering purposes. As it yields to similar results for the given experiments, it can be used as a rough simplification of the double-diffusion model. Simulations were performed with Eq. 2 (with a corresponding density of sorption sites), and the reduction factor for the water vapour diffusion coefficient was lowered to $\xi=0.4$ to get comparable results. Length of diffusion inside the sample bowl was chosen identical to the value for the double-diffusion approach (i.e. $H_{\mathrm{A}}+H_{\mathrm{S}}=0.6 H_{\mathrm{B}}$ ). With a few exceptions, the measured results show a similar behaviour as predicted by the simulations. This indicates the relevance of WVT on the temperature dependence of the 


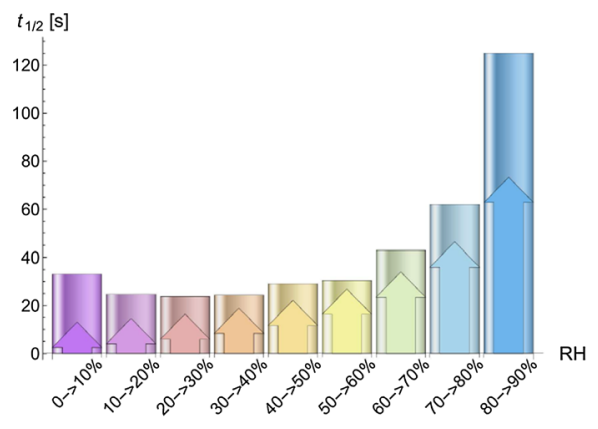

(a)

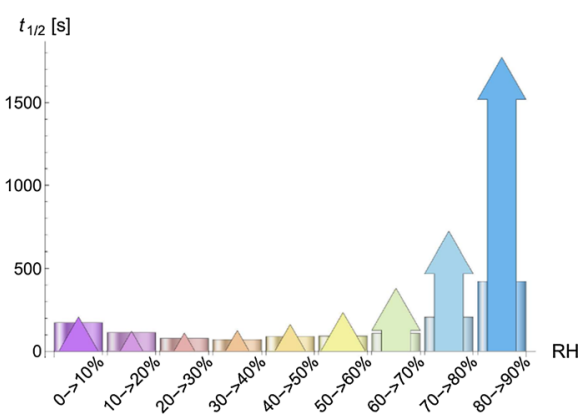

(b)

Fig. 8 Characteristic RH equilibration half-times of the sorption analyser for a step change of $\Delta \mathrm{RH}=10 \%$ at $T=25^{\circ} \mathrm{C}$. Measured half-times without sample material (a) and with a total sample mass of approximately $10 \mathrm{~g}$ (b) are shown with bars, and arrows indicate the simulated effect of moisture displacement. Errors were omitted for a better comparability

sorption kinetics. The increasing split-up with temperature in the high (adsorption) and low (desorption) range of $\mathrm{RH}$ might be a consequence of the moistening process. Comparing the results for a step size of $\Delta \mathrm{RH}=30 \%$ with $\Delta \mathrm{RH}=10 \%$, the former shows a better conformity between the measured and simulated data (except for the last step change in adsorption; see Fig. 7c). This seems reasonable if processes within the cell wall of wood are less dominant for larger step sizes in RH, which has already been found for small cut samples starting from dry conditions (Christensen and Kelsey 1959). Similar results were also obtained for the $250-500 \mu \mathrm{m}$ grain size distribution.

\subsection{Moistening Method}

Analysing the water vapour supply during a step change in $\mathrm{RH}$, care has to be taken about the specific method of changing humidity inside the measuring chamber. This seems less obvious when treating the sorption kinetics of hygroscopic materials, but becomes particular important for adsorption at high RH and for desorption at low RH. Figure 8a shows the comparison of timescales to reach half of the target humidity during a step change of $\Delta \mathrm{RH}=10 \%$ without using any sample material. Evaluation time was chosen to reach half of the step change in RH to avoid the automatic regulation mechanism of the moistening unit (to prevent overshooting). An exponential increase can be seen which becomes dominant in the high range of RH for adsorption, and a similar behaviour was observed for desorption in the low range of RH. As no sample material was placed inside the measuring chamber, these differences in the $\mathrm{RH}$ equilibrium times seems to be a consequence of the moistening process of the sorption analyser. Using Eq. 11 with a supply rate of saturated air $r_{\mathrm{I}}=2.4 \mathrm{dm}^{3} \mathrm{~min}^{-1}$, an inflow with $\mathrm{RH}_{\mathrm{I}} \approx 99 \% \mathrm{RH}$ and an estimated effective volume $V_{\mathrm{M}}=10.2 \mathrm{dm}^{3}$ (i.e. approximate gas volume inside the measuring chamber), the corresponding RH equilibrium half-times were calculated and are shown as arrows in Figure 8a. The increasing trend can be roughly captured, and the deviations might result from the simplified assumption of an instantaneous mixing of the inflow with the humidity inside the chamber. Similar results were obtained for the desorption process, where the RH equilibration half-times increase towards the low range of $\mathrm{RH}$. The higher value of the measured $\mathrm{RH}$ equilibration time in the first step change (i.e. $0 \% \rightarrow 10 \% \mathrm{RH}$ ) seems to be caused by a delayed moisture regulation of the sorption 
analyser. It should be noted that a sorption system where the set RH is directly injected into the measuring chamber (i.e. pre-mixing of dry and water vapour-saturated air; see, for example, Hill et al. 2010b) would lead to longer but similar equilibrium times along the range of humidity, if the same flow rate and measuring volume is used (cf. Eq. 11). An additional effect, which is more relevant for the local distribution of $\mathrm{H}_{2} \mathrm{O}$ molecules is given by the local moisture gradient during a step change in $\mathrm{RH}$. With an influx of water vapoursaturated air, the gradient between the water vapour concentration in the measuring chamber and the influx decreases with increasing humidity. Hence, for measuring systems which use a stream of water vapour-saturated or dry air to regulate humidity, the local equilibration of moisture during a step change in RH is decreasing with increasing humidity for adsorption and vice versa for desorption. This effect is less significant than the before-mentioned moisture displacement, and a proper treatment would need a detailed knowledge on the geometry inside the measuring chamber.

Regarding the influence of water vapour supply on wood (or any other highly hygroscopic sample material) during a step change in $\mathrm{RH}$, the exponential increasing $\mathrm{RH}$ equilibration time will slow down the initial sorption kinetics for both small and large samples. Above a certain amount of sample material in the measuring chamber, additional care has to be taken on the amount of $\mathrm{H}_{2} \mathrm{O}$ molecules taken up/being released by the sample. Considering Eq. 12, the large mass uptake/release in the low and high range of RH (Fig. 3b) should slow down the change of humidity during a step change in the chamber. Analysing a separate experimental set-up with a total amount of $10 \mathrm{~g}$ of wood spread over 11 sample bowls, the retardation on RH equilibration time is clearly shown in Fig. 8b. Using Eq. 13 for the given sorption analyser and choosing $x=0.5$, the RH equilibrium half-times can be calculated and are shown as arrows in Fig. 8b. The deviation in the high range of humidity might be related to the relevance of other processes within the cell wall (see, for example, Wadsö 1994a). For desorption, the deviation between measured and simulated results is noticeable lower (not shown). A corresponding investigation for the experimental set-ups presented in this work was not possible as a separate measuring procedure has to be used. Consequently, the sorption kinetics will be influenced by the rate and $\mathrm{RH}$ of the inflow, measuring and sample volume, as well as range and step size in RH. For a reliable study on the sorption kinetics of small wooden samples (or other highly hygroscopic materials), humidity should be changed as fast as possible during a step change in $\mathrm{RH}$. If a threshold for the equilibration half-time is set to $1 \mathrm{~min}$, a maximum value for the total sample mass of approximately $2 \mathrm{~g}$ would be acceptable with the given measuring set-up. Comparing the influence of mass change (Fig. 3b) on the RH equilibration times (Fig. 8b) and the variation in characteristic time for the fast process in the PEK model (Hill et al. 2010b, 2011a; Sharratt et al. 2011; Popescu et al. 2014; Himmel and Mai 2015) suggests the fast process to be influenced by the water vapour supply.

\subsection{Paths of Stagnant Air}

To analyse the effect of an additional diffusion path between the forced water vapour-air stream and the sample surface on the sorption kinetics of grained wood (see Sect. 2.2), various grain layer filling levels were compared and are shown in Fig. 9. A variation in split-up of the WVS kinetics between the different grain layer fillings over the range of humidity can be seen for adsorption and desorption. Corresponding to the smaller amount of $\mathrm{H}_{2} \mathrm{O}$ uptake/release of wood in the medium range of $\mathrm{RH}$ (for a given step size in $\mathrm{RH}$ ), a faster mass increase can be observed compared to the low and high range of RH. The sorption kinetic curves were evaluated at $t_{\mathrm{ev}}=15 \mathrm{~min}$ and standardised to the results of 


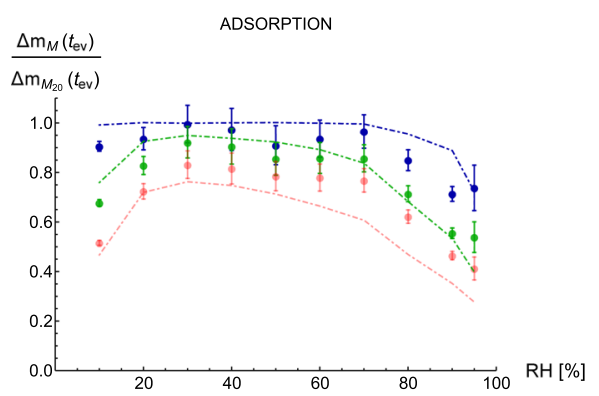

(a)

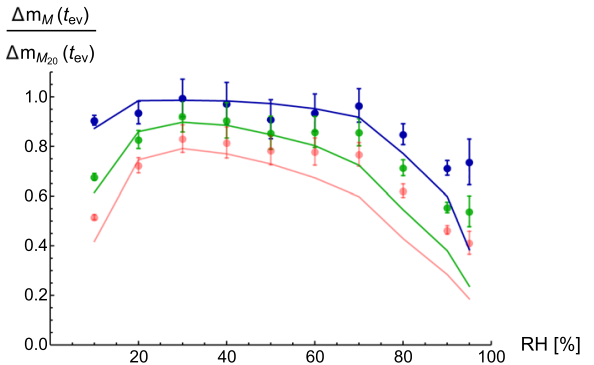

(c)

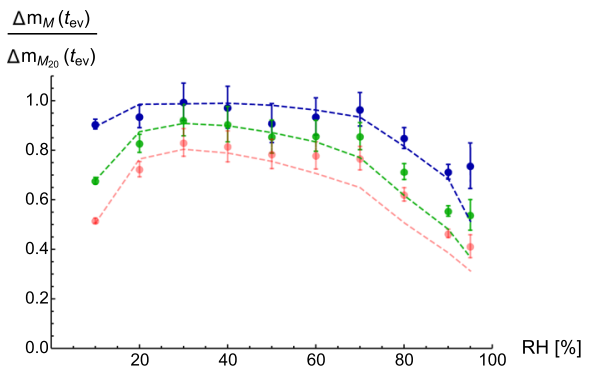

(e)

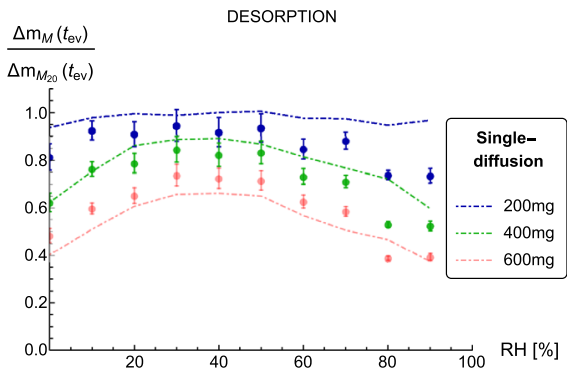

(b)

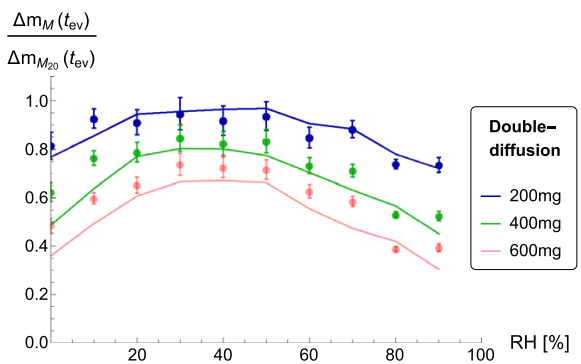

(d)

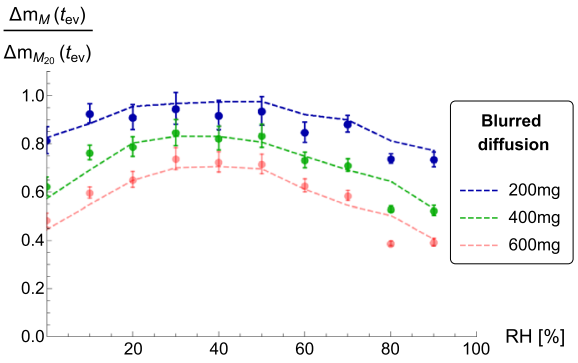

(f)

Fig. 9 Comparison of the split-up of WVS kinetic curves between various grain layer filling levels along the relative humidity for adsorption $(\mathbf{a}, \mathbf{c}, \mathbf{e})$ and desorption $(\mathbf{b}, \mathbf{d}, \mathbf{f})$. Markers indicate the measured values and dot dashed/solid/dashed lines the corresponding solutions for the single-diffusion (a, b), double-diffusion (c, d) and blurred diffusion $(\mathbf{e}, \mathbf{f})$

the $20 \mathrm{mg}$ sample. When analysing the data with a single-diffusion equation (Eq. 2) without considering the additional diffusive transport path $H_{\mathrm{A}}$ (i.e. sample surface is assumed to be in direct contact with the forced water vapour air stream), the split-up between the kinetic curves of the various samples cannot be captured correctly (Fig. 9a, b). The calculated kinetics of the $200 \mathrm{mg}$ sample $\left(H_{\mathrm{S}}=0.68 \mathrm{~mm}\right)$ were found to be faster than the measured results, whereas those of the $600 \mathrm{mg}$ sample $\left(H_{\mathrm{S}}=2.0 \mathrm{~mm}\right)$ were found to be slower. In order to compare the simulations with the measured results, the reduction factor for the water vapour diffusion coefficient was lowered to $\xi=0.09$ as this model would lead to a much faster kinetic. It might be noted that even though the sorption kinetics would be slowed down with the use of a non-instantaneous sink, the delayed availability of sorption sites (e.g. caused by relaxation 
and reorganisation processes) should cause a different behaviour. Thinner samples are more affected by the availability of sorption sites than thicker ones, as a diffusion process scales to the square of sample thickness $\left(\sim H_{\mathrm{S}}^{2}\right)$ and becomes more dominant for thicker samples. Hence, the sorption kinetic curves of low grain layer filling levels (i.e. low mass) should be delayed and positioned closer together, whereas samples with higher filling levels (i.e. larger mass) should approximately show the characteristic behaviour given by the diffusion equation. As the experimental results show a converse trend (i.e. a larger split-up for thinner samples than for the thicker ones; see Fig. 9a, b), a consideration of the diffusive transport path between the forced water vapour-air stream and the sample surface seems to be important for modelling the sorption kinetics of small wooden samples. Comparing the experimental results with the double-diffusion approach, a better conformance was observed (Fig. 9c, d). Simulations were performed similar to Sect. 4.3. The decreasing trend for the split-up with sample mass between the WVS kinetic curves could be roughly captured, which points towards the anomalous behaviour of grained wood being influenced by the additional water vapour transport path to the sample surface. An increasing deviation between measured results and the simulations can be seen for adsorption in the medium to high range of RH (Fig. 9c). This might indicate that processes within the cell wall of wood are more relevant at medium to high humidity levels, which has already been mentioned in the literature (e.g. Christensen and Kelsey 1959; Wadsö 1994a). The desorption kinetics show a better conformance between the experiments and simulations, which seems to be consistent with the notion of creating new sorption sites during adsorption. Regarding the additional diffusion path, there might be a connection to the concept of an external resistance, which was frequently used in the earlier literature (e.g. Avramidis and Siau 1987 and references therein). In addition, the blurred diffusion approach (see Sect. 4.3) was used to model the WVT in WVS experiments for various grain layer filling levels. As shown in Fig. 9e, f, a similar conformance between the measured and simulated results was obtained. Similar to the double-diffusion approach, a deviation in the medium to high range of RH can be seen for adsorption (Fig. 9e). Conversely, the desorption kinetics show a better conformance (Fig. 9f). The deviation of experimental results for the step change $90 \% \rightarrow 80 \% \mathrm{RH}$ might be related to, or caused by, the smaller prior step change $(95 \% \rightarrow 90 \% \mathrm{RH})$. Given the congruence of the measured and simulated results, it appears that the diffusion path both to the sample surface and through the sample influence the sorption kinetics of grained wood.

\section{Conclusion}

Water vapour transport has a significant effect on the sorption kinetics of wood and has to be considered even for small sample sizes. This was shown by a simplified analysis on the diffusion of water vapour through wood and comparing the results with the measured water vapour sorption kinetics of grained wood. The diffusion of water vapour through the macrostructure is markedly reduced by the uptake or release of $\mathrm{H}_{2} \mathrm{O}$ molecules of the surrounding cell walls, which decreases the effective diffusion coefficient to a similar magnitude as used for bound water diffusion in wood. Because of the nonlinear isotherm, this effective diffusion coefficient depends on step size and range of relative humidity. The marked impact of temperature on the measured kinetics (during a step change in relative humidity) seems to be a consequence of the temperature-dependent concentration of $\mathrm{H}_{2} \mathrm{O}$ molecules in the air. A further effect found is placing the sample material into bowls for the measurement causes a delay in the water vapour transport, which becomes apparent in an anomalous split-up of 
the sorption kinetics for grained wood with different grain layer filling levels. Consequently, an interpretation of the water vapour sorption kinetics for hygroscopic materials without including the transport of water vapour leads to incorrect values and dependencies of the corresponding model parameters. Based on this study, future research should combine the given water vapour transport with a transport through the cell wall and an appropriate model for the uptake/release of $\mathrm{H}_{2} \mathrm{O}$ molecules, to model and interpret the sorption kinetics of small wooden samples.

Acknowledgements Open access funding provided by University of Innsbruck and Medical University of Innsbruck. This work has been funded by the Research Program Translational Research of the Standortagentur Tirol under the Project DigiPore3D and the grant Doktoratsstipendium NEU aus der Nachwuchsförderung by the Universität Innsbruck, Vizerektorat für Forschung, under the code 2015/2/TECH-26. Their financial support is gratefully acknowledged.

Open Access This article is distributed under the terms of the Creative Commons Attribution 4.0 International License (http://creativecommons.org/licenses/by/4.0/), which permits unrestricted use, distribution, and reproduction in any medium, provided you give appropriate credit to the original author(s) and the source, provide a link to the Creative Commons license, and indicate if changes were made.

\section{References}

Alduchov, O.A., Eskridge, R.E.: Improved magnus form approximation of saturation vapor pressure. J. Appl. Meteorol. 35(4), 601-609 (1996)

Avramidis, S., Siau, J.F.: An investigation of the external and internal resistance to moisture diffusion in wood. Wood Sci. Technol. 21(3), 249-256 (1987)

Barrie, J.A., Platt, B.: The diffusion and clustering of water vapour in polymers. Polymer 4(C), 303-313 (1963)

Bird, B.R., Steward, W.E., Lightfood, E.N.: Transport Phenomena, 2nd edn. Wiley, New Jersey (2002)

Crank, J.: The Mathematics of Diffusion, 2nd edn. Oxford University Press, Oxford (1975)

Christensen, G.N., Kelsey, K.E.: Die Geschwindigkeit der Wasserdampfsorption durch Holz [The rate of sorption of water vapour by wood]. Eur. J. Wood Wood Prod. 17(5), 178-188 (1959)

Eitelberger, J., Svensson, S.: The sorption behavior of wood studied by means of an improved cup method. Transp. Porous Media 92(2), 321-335 (2012)

Eitelberger, J., Hofstetter, K., Dvinskikh, S.V.: A multi-scale approach for simulation of transient moisture transport processes in wood below the fiber saturation point. Compos. Sci. Technol. 71(15), 1727-1738 (2011)

Frandsen, H.L., Damkilde, L., Svensson, S.: A revised multi-Fickian moisture transport model to describe non-Fickian effects in wood. Holzforschung 61(5), 563-572 (2007)

Glass, S.V., Boardman, C.R., Zelinka, S.L.: Short hold times in dynamic vapor sorption measurements mischaracterize the equilibrium moisture content of wood. Wood Sci. Technol. 51(2), 243-260 (2017)

Gouanvé, F., Marais, S., Bessadok, A., Langevin, D., Morvan, C., Métayer, M.: Study of water sorption in modified flax fibers. J. Appl. Polym. Sci. 101(6), 4281-4289 (2006)

Hailwood, A.J., Horrobin, S.: Absorption of water by polymers: analysis in terms of a simple model. Trans. Faraday Soc. 42, 84-92 (1946)

Himmel, S., Mai, C.: Effects of acetylation and formalization on the dynamic water vapor sorption behavior of wood. Holzforschung 69(5), 633-643 (2015)

Himmel, S., Mai, C.: Water vapor sorption of wood modified by acetylation and formalization-analyzed by a sorption kinetics model and according to modeless thermodynamic considerations. Holzforschung 70(3), 203-213 (2016)

Hozjan, T., Svensson, S.: Theoretical analysis of moisture transport in wood as an open porous hygroscopic material. Holzforschung 65, 97-102 (2011)

Hill, C.A.S., Norton, A., Newman, G.: Analysis of the water vapour sorption behaviour of Sitka spruce based on the parallel exponential kinetics model. Holzforschung 64, 469-473 (2010a)

Hill, C.A.S., Norton, A.J., Newman, G., Hill, C.A.S., Norton, A.J., Newman, G.: The water vapour sorption properties of Sitka spruce determined using a dynamic vapour sorption apparatus. Wood Sci. Technol. 44, 497-514 (2010b) 
Hill, C.A.S., Moore, J., Jalaludin, Z., Leveneu, M., Mahrdt, E.: Influence of earlywood/latewood and ring position upon water vapour sorption properties of Sitka spruce. Int. Wood Prod. J. 2(1), 12-19 (2011a)

Hill, C.A.S., Ramsay, J., Keating, B., Laine, K., Rautkari, L., Hughes, M., Constant, B.: The water vapour sorption properties of thermally modified and densified wood. J. Mater. Sci. 47(7), 3191-3197 (2011b)

Krabbenhoft, K., Damkilde, L.: A model for non-Fickian moisture transfer in wood. Mater. Struct./Mater. Constr. 37(273), 615-622 (2004)

Murr, A., Lackner, R.: Analysis on the influence of grain size and grain layer thickness on the sorption kinetics of grained wood at low relative humidity with the use of water vapour sorption experiments. Wood Sci. Technol. 52(3), 753-776 (2018)

Olek, W., Weres, J.: Effects of the method of identification of the diffusion coefficient on accuracy of modeling bound water transfer in wood. Transp. Porous Media 66(1-2), 135-144 (2007)

Olek, W., Perré, P., Weres, J.: Inverse analysis of the transient bound water diffusion in wood. Holzforschung 59(1), 38-45 (2005)

Penman, H.L.: Gas and vapour movements in the soil: I. The diffusion of vapours through porous solids. J. Agric. Sci. 30(3), 437-462 (1940)

Popescu, C.M., Hill, C.A.: The water vapour adsorption-desorption behaviour of naturally aged Tilia cordata Mill. wood. Polym. Degrad. Stab. 98(9), 1804-1813 (2013)

Popescu, C.M., Hill, C.A., Curling, S., Ormondroyd, G., Xie, Y.: The water vapour sorption behaviour of acetylated birch wood: How acetylation affects the sorption isotherm and accessible hydroxyl content. J. Mater. Sci. 49(5), 2362-2371 (2014)

Popescu, C.M., Hill, C.A., Anthony, R., Ormondroyd, G., Curling, S.: Equilibrium and dynamic vapour water sorption properties of biochar derived from apple wood. Polym. Degrad. Stab. 111, 263-268 (2015)

Rosen, H.N.: The influence of external resistance on moisture adsorption rates in wood. Wood Fiber Sci. 10(3), 218-228 (1978)

Schirmer, R.: Die Diffusionszahl von Wasserdampf-Luftgemischen und die Verdampfungsgeschwindigkeit. Zeitschrift des Vereins deutscher Ingenieure (VDI Beiheft) 6(70), 170-177 (1938)

Siau, J.F.: Tranport Processes in Wood. Springer, Berlin (1984)

Stanish, M.A.: The roles of bound water chemical potential and gas phase diffusion in moisture transport through wood. Wood Sci. Technol. 20(1), 53-70 (1986)

Skaar, C., Babiak, M.: A model for bound-water transport in wood. Wood Sci. Technol. 16(2), 123-138 (1982)

Sharratt, V., Hill, C.A., Zaihan, J., Kint, D.P.: The influence of photodegradation and weathering on the water vapour sorption kinetic behaviour of scots pine earlywood and latewood. Polym. Degrad. Stab. 96(7), 1210-1218 (2011)

Thorvaldsson, K., Janestad, H.: A model for simultaneous heat, water and vapour diffusion. J. Food Eng. 40, 167-172 (1999)

VDI-Gesellschaft (ed) VDI-Wärmeatlas, 10th edn. Springer, Berlin (2006)

Wadsö, L.: Measurements of water vapour sorption in wood. Wood Sci. Technol. 28(1), 59-65 (1993a)

Wadsö, L.: Studies of water vapor transport and sorption in wood. PhD thesis, Lund University (1993b)

Wadsö, L.: Describing non-Fickian water-vapour sorption in wood. J. Mater. Sci. 29(9), 2367-2372 (1994a)

Wadsö, L.: Unsteady-state water vapor adsorption in wood: an experimental study. Wood Fiber Sci. 26(1), 36-50 (1994b)

Publisher's Note Springer Nature remains neutral with regard to jurisdictional claims in published maps and institutional affiliations. 